\title{
Evaluating the Effect of Six Weeks Strength Training on the Speed of Sprinters Among Debre Markos University Male Sport Science Students, Ethiopia
}

\author{
Awoke Tibebu ", Mekuriaw Demeke, Birhanu Anjetie \\ Department of Sport Science, College of Natural and Computational Science, Debre Markos University, Debre Markos, Ethiopia \\ Email address: \\ awoket27@gmail.com(A. Tibebu), yismaw36@gmail.com(M. Demeke), enubrish@gmail.com(B. Anjetie) \\ ${ }^{*}$ Corresponding author
}

To cite this article:

Awoke Tibebu, Mekuriaw Demeke, Birhanu Anjetie. Evaluating the Effect of Six Weeks Strength Training on the Speed of Sprinters Among Debre Markos University Male Sport Science Students, Ethiopia. International Journal of Science, Technology and Society.

Vol. 8, No. 5, 2020, pp. 100-104. doi: 10.11648/j.ijsts.20200805.12

Received: January 21, 2020; Accepted: August 27, 2020; Published: September 10, 2020

\begin{abstract}
Purpose: The purpose of this study was to investigate the effects of six weeks strength training interventions on speed performance of sprinters. Furthermore, the purpose was to compare the effects of strength training on some anthropometry of sprinters among University sport science students. Methods: To achieve the purpose of the study, six male student athletes were selected as subjects purposively. The study was formulated as experimental (pre and post-test) study design. All Selected subjects participated on proposed exercises training program for six consecutive weeks, with four days per week for a total of thirty two training sessions. The outcome variables were measurement of calf, thigh, chest, biceps and triceps circumference and $100 \mathrm{~m}$ and $200 \mathrm{~m}$ speed. The data were analyzed using paired t-test with comparison of means at $95 \%$ confidence intervals. Results: The results indicated there were significant improvement on selected variables weight, biceps and triceps muscle circumference and speed of $100 \mathrm{~m}$ and $200 \mathrm{~m}(\mathrm{p}<0.05)$. In other variables like calf, thigh, and chest had a change but significant differences were not observed. The mean differences (MD) between pre and post tests for weight were 1.4 , biceps triceps 2.5 , chest 0.5 thigh 0.833 , calf 0.5 and speed of $100 \mathrm{~m} 0.143,200 \mathrm{~m} 0.6$. Conclusion: This study confirmed that strength training has an impact on speed and anthropometry. The study showed that student athletes who were exposed to six weeks strength exercise training have positive outcomes on speed.
\end{abstract}

Keywords: Agility, Athlete, Balance, Coordination, Reaction Time, Speed, Strength, Training

\section{Introduction}

Speed is a fine motor skill that can be increased by applying principle of motor learning to speed training. [1] A rapid movement from one place to another place is required in many athletic activities especially in sprint running. [2] A successful sprinter must have the ability to exert great force against the surface of the ground in a shorter time period than a less successful sprinter, which indicates that the successful sprinter generates greater power or ground reaction forces. [3]

A sprinter performance is mainly determined by the force and speed with which muscle can contract and relax because of the cyclic motion, the correct time of the change from contraction (force application) to relaxation. [4] Resisted sprint training is used to increase force output at the ankle, knee and hip in and effect to increase stride length. [5] Exercises that enhance strength capacities are imperative in improving competitive sprinting performance. $[6,7]$ Besides neurological and morphological changes which means an increase in mitochondrial contents results force production improved since ATP is found in mitochondria. [15, 25, 34]

Strength and conditioning programs has a potential effects and outcomes on athletic performance. Although quadriceps, hamstrings and calf muscles are chiefly responsible for propelling the body forward during running and jumping exercise, hip flexor muscles also contribute to bring the free leg forward and upward during the sprinting in recovery phase. [8] The effects of strength training on sprinting performance has been well acknowledged in a number of 
studies with the majority reporting improved running performance. [9, 13-16] A proper integration of a periodized resistance-training and speed-training program can cause such positive adaptations. [10] Besides, some research studies showed that there is a high correlation between the leg power and sprint ability by using horizontal and vertical jump displacements as an indirect power measurement. [11]

\section{Materials and Methods}

\subsection{Participants}

Six male sprinters on a university short distance running team volunteered to participate in this study and their basic physical characteristics, related body composition, and physiological indicators are taken in to consideration while selecting of subjects. All the participants competed at the Ethiopian public university sport association short distance event competition they had a minimum of three years of training experience for short distance running and were free from injury. They stayed and trained together at the training center affiliated with the Debre Markos University in the department of Sport science, thus having similar training, recovery, and nutritional environments. All participants were free from any health problems that would affect physical performance or put them at risk.

\subsection{Procedure}

In both pre-test and post-tests variables of anthropometry of selected student athletes (chest, biceps triceps, thigh, calf muscle circumference and their weight) were measured. As well as 10 minutes of warming-up exercise was done starting from easy to moderate intensity running on the track with 8 minutes of dynamic warming up exercise. After completing warming up $100 \mathrm{~m}$ and $200 \mathrm{~m}$ sprint performances were assessed on separate days, 24 hours apart in an outdoor cinder running track. The subjects were asked to run as fast as possible, strong verbal encouragement was provided during all tests to motivate participants to give a maximal effort. Each of the participants abstained from training prior to testing. Due to testing being conducted on different days all assessments were conducted at the same time of day and the participants asked to standardize their food and fluid intake prior to each testing session. The posttest sessions were performed at the same venue and time of day ( \pm 1 hour) for each participant under the same environmental conditions.

\subsection{Training Intervention}

All subjects completed an individualized strength training program four days per week for six weeks (a total of 36 sessions). Loads were set as a percentage of the pre-test values. The volume load of sessions was manipulated through the repetitions and sets performed to divide the sessions into a high volume and low volume day throughout the week. Strength training were selected due to the strong associations with maximal strength in this exercise and $100 \mathrm{~m}, 200 \mathrm{~m}$ sprint performances both maximal strength and sprint performances were reassessed at the end of the six week training intervention using the same protocols.

\subsection{Statistical Analysis}

Following data collection and analyses, means and standard deviations were calculated for all results. A paired samples t-test was used to determine if there was a significant difference between pre and post protocol of strength training and $100 \mathrm{~m}$ and $200 \mathrm{~m}$ sprint times. Statistical analysis was conducted using SPSS v20.0 statistical software package with a statistical significance level set at $\mathrm{p}<0.05$.

\subsection{Results}

The strength and speed training was provided for six weeks with the frequency of 4 days. The selected variables were measured two times before (pre) training test and after (post) training test. The outcome variables were; weight, calf, thigh, chest, biceps and triceps muscle circumferences and $100 \mathrm{~m}, 200 \mathrm{~m}$ speed.

Table 1. The pre and post training test results for mass, Biceps triceps, Thigh and Calf circumference, $100 \mathrm{~m}$ and $200 \mathrm{~m}$ speed (values are mean \pm SD (standard deviation).

\begin{tabular}{|c|c|c|c|c|c|}
\hline Variables & $\mathbf{N}$ & PT & POT & mean difference & Significance \\
\hline Mass (kg) & 6 & $59.5 \pm 1.99$ & $60.9 \pm 1.68$ & 1.4 & $0.017 *$ \\
\hline Biceps triceps circumference & 6 & $25.8 \pm 0.75$ & $28.3 \pm 1.4$ & 2.5 & $0.01 *$ \\
\hline Chest circumference & 6 & $90.83 \pm 1.169$ & $91.33 \pm 0.816$ & 0.500 & $0.415^{*}$ \\
\hline Thigh circumference & 6 & $47.50 \pm 2.588$ & $48.33 \pm 1.633$ & 0.833 & $0.363^{*}$ \\
\hline Calf circumference & 6 & $32.83 \pm 1.472$ & $33.33 \pm 1.633$ & 0.500 & $0.76^{*}$ \\
\hline $100 \mathrm{~m}$ speed & 6 & $12.38 \pm 0.47$ & $12.22 \pm 0.51$ & 0.143 & $0.014 *$ \\
\hline $200 \mathrm{~m}$ speed & 6 & $26.52 \pm 1.114$ & $26.468 \pm 1,083$ & 0.600 & $0.036^{*}$ \\
\hline
\end{tabular}

$\mathrm{PT}=$ Pre training test; POT $=$ Post training test, $\mathrm{P}<0.05^{*}$ significance and the data in the form of mean $\pm \mathrm{ST}$ (standard deviation).

A paired samples t-test showed the six weeks strength training protocol elicited statistically significant improvement in the Mass of the subjects. The mean of the pre-test was 59.5, and the mean of the post-test was 60.9 . Therefore the mean difference in Mass was 1.4.

The pre and post-test mean values for biceps triceps muscle circumference was 25.8 and 28.3 respectively its level of significance was high. In other hand No significant improvements were detected on chest $(p>0.05)$ their significance value is $(0.415)$ the pre and post training mean values of a chest muscle size was 90.83 and 91.33 respectively 
No significant differences were observed on thigh muscles size because $(p>0.05)$ the pre and post training mean value for thigh muscle was 90.83 and 91.33 respectively. The mean value difference of thigh muscle was $(0.500)$ even if an improvement was observed.

The data from the above table showed that there was not a significance improvement in their calf muscle size because $p>0.05$. Their significance value is 0.76 , but the pre and post training mean values for calf muscle size was 32.83 and 33.33 respectively and the mean value difference was 0.05 this was not much significant.

The $100 \mathrm{~m}$ running time data are presented in the above table was 12.38 and 12.22 respectively. The mean difference for the speed $100 \mathrm{~m}$ was $(0.0143)$ then post training test had greater speed than pre training test by $(0.014)$ were observed.

Paired t-tests result showed that significant differences were observed in $200 \mathrm{~m}$ sprint speed26.52 and 26.468 respectively. As the pre and posttest mean values for $200 \mathrm{~m}$ sprinting had greater change than pre training test.

\section{Discussion}

The major findings in this study was the observed significance relationship between strength training and sprinting performance and also this finding highlight the initial influence of strength training and changes come up on lean body mass after training for speed/power activities. These results are in agreement with previous studies, Success in sprinting is based on great force exertion against the surface of the ground in a shorter time period. Strength trainings have the key role to handle body weight, resist gravity, and optimize ground reaction forces. [17, 32, 33, 36] Evidence to support this view has come from [36] the addition of greater muscle mass in both the upper and lower body seems to positively enhance performance with no negative side effects related to an increased body mass. [36] A number of studies have demonstrated the significance of both maximal strength and speed strength training in sprinters' performance. [18-22] In another study, which assessed the effects of a nine-week program, the researchers confirmed a significant improvement in subjects' sprinting performance as well as arm strength after maximal effort strength training. [23] An increase in maximum isometric strength would be expected to lead to a proportional increase in strength at all velocities of shortening and consequently an increase in the maximum power developed. [24, 30] The above idea supported by several studies, repeated resistance exercise can enhance mitochondrial content and function. $[15,25,34]$ One of the most profound effects of strength exercise is an increase in mitochondrial content. It Increases up to $50 \%$ after only $6-8$ weeks of training. [35]

Body composition plays a crucial role in the start, acceleration/attainment of maximal velocity, and maintenance of velocity. [37, 39] This is likely due to stronger athletes developing higher peak ground reaction force and impulse, which have been shown to be strong determinants of sprint performance. [11,32, and 33] Good associations are also reported between maximum ground reaction force and maximal sprinting velocity $(r=0.60)$ [32], suggesting that increasing strength, or maximal force production, may also improve acceleration and maximal sprinting velocity. In fact Speed is a product of stride length and stride frequency. Both of these sprinting parameters are related to the athlete's height and/or limb length. Height is related with stride length in sprinters [37], while the influence of stride frequency is a function of the trade-off between the ability of the leg to maximize ground reaction forces and minimize moments of inertia. [17, 38, 40]

The results of this study support a positive effect of this training method on sprinters. Therefore, it can be stated that movement velocity used as a main training criterion has great potential to induce beneficial strength adaptations and improve athletic performance. [17-19, 31] Increases in lower-body strength transfer positively to sprint performance, so the combined training method (resistance training along with sprints) focused on maximal execution velocities seems to be an optimal training strategy to improve sprint performance. [28, 31, 36] Based on the finding of this study, six weeks strength training program can improve sprint (100 and $200 \mathrm{~m}$ ) performance this training method could increase muscular force output so as to improve sprinting speed, Meanwhile explosive speed is required in short distance running events.

In general, Speed in athletics is influenced by stride cadence and frequency of all body movements. From the two factors this study mainly focuses on the improvements of stride frequency. Many different training methods have been used to improve sprinting performance among strength training is one of the methods used to improve stride frequency. Because of an increment in skeletal muscle size (hypertrophy) has a direct relationship with the mitochondrial contents since ATP is found in the power house of the cell.

\section{Conclusions}

This investigation aimed to evaluate the effects of six weeks strength training protocols on sprinting performance, Although the subjects included during the study significantly improved $100 \mathrm{~m}$ and $200 \mathrm{~m}$ sprint time following the intervention, it is difficult to be sure that the intervention is truly responsible for this result. The findings highlight the six weeks strength training effects in substantially enhancing speed performance in university student athletes, particularly when the intervention is an additional to large volumes of training being concurrently performed. However, the results also indicate promise for the use of strength training as a means of inducing novel stimuli for the enhancement of short distance sprint performance.

\section{Acknowledgements}

We would like to thank all the students who took the time to complete the experiment. 


\section{References}

[1] Gambeta V, 2007 Athletic development, The art and science of functional sports conditioning.

[2] Pinero, J. C., Montesinos, J. L. G., Keating, X. D., Mora, J., Sjostrom, M. \& Ruiz, J. R. (2010). Percentile values for running sprint field tests in children ages 6-17 years: influence of weight status. Research Quarterly for Exercise and Sport, 81 (2), 143-151.

[3] Ward Smith A, J and D. F Radiford 2000, Investigation of the kinetics of anaerobic metabolism by analysis of the performance of elite sprinters, Biomech, 33.

[4] Schmolisky, G 1983 track and field sport Verla berlin.

[5] Lockie, RG., Murphy, AJ., \& Spinks, C. (2003). Effects of Resisted Sled Towing on Sprint Kinematics in Field-Sport Athletes. JSCR, 2003; 17 (4): 760-767, doi: 10.1519/15334287.

[6] Folland JP, Williams AG. The adaptations to strength training: morphological and neurological contributions to increased strength. Sports Med. 2007; 37 (2): 145-168. PubMed doi: 10.2165/00007256-200737020-00004.

[7] Gabriel DA, Kamen G, Frost G. Neural adaptations to resistive exercise: mechanisms and recommendations for training practices. Sports Med. 2006; 36 (2): 133-149. PubMed doi: 10.2165/00007256-200636020-00004.

[8] Kale, M., Asci, A., Bayrak, C. \& Acikada, C. (2009). Relationships among jumping performances and sprint parameters during maximum speed phase in sprinters. Journal of Strength and Conditioning Research, 23 (8), 2272-2279.

[9] Gamble 2010 strength and coordination for team sports specific physical preparation for high performance, new work, NY: Rutledge.

[10] Hoff J, Gran A, Helgerud J. Maximal strength training improves aerobic endurance performance. Scand J Med Sci Sports. 2002; 12 (5): 288-295. PubMed doi: 10.1034/j.16000838.2002.01140.x.

[11] Habibi, A, shabani, M., Rahimi, E. Fatemi, R., Najiafi (2010), Relationship between jump test results and acceleration phase of sprint performance in national and regional $100 \mathrm{~m}$ sprinters journal of Human Kinetics 23, 29-35.

[12] Cook G 2003 athletic body in balance Champaign 11, human kinetics.

[13] Kyröläinen, H., Avela, J., \&Komi, P. V. (2005). Changes in muscle activity with increasing running speed. Journal of sports sciences, 23 (10), 1101-1109.

[14] McBride, J. M., Blow, D., Kirby, T. J., Haines, T. L., Dayne, A. M., \& Triplett, N. T. (2009). Relationship between maximal squat strength and five, ten, and forty yard sprint times. The Journal of Strength \& Conditioning Research, 23 (6), 16331636.

[15] McMahon, G. E., Morse, C. I., Burden, A., Winwood, K., \&Onambélé, G. L. (2014). Impact of range of motion during ecologically valid resistance training protocols on muscle size, subcutaneous fat, and strength. The Journal of Strength \& Conditioning Research, 28 (1), 245-255.
[16] Morin, J. B., Slawinski, J., Dorel, S., Couturier, A., Samozino, P., Brughelli, M., \&Rabita, G. (2015). Acceleration capability in elite sprinters and ground impulse: Push more, brake less? Journal of biomechanics, 48 (12), 3149-3154.

[17] Will Freeman, Track \& Field coaching essentials / USA Track \& Field; Human Kinetics, ISBN: 978-1-4504-8932-4, 2015 USATF Properties, LLC.

[18] GIORGOS DASTERIDIS, THEOPHILOS PILIANIDIS, NIKOS MANTZOURANIS, THE EFFECT OF DIFFERENT STRENGTH TRAINING PROGRAMS ON YOUNG ATHLETES' SPRINT PERFORMANCE, STUDIES IN PHYSICAL CULTURE AND TOURISM Vol. 18, No. 2, 2011.

[19] Conroy T. R., Plyometric training and its effects on speed, strength, and power of intercollegiate athletes, Microform Publication, 1994, University of Oregon, Eugene, pp. 38-45.

[20] Garhammer J., Gregor R., Propulsion forces as a function of intensity for weightlifting and vertical jumping, Journal of Applied Sport Science and Research, 1992, vol. 6, pp. 129-134.

[21] Young W., Bildy G., The effect of voluntary effort to influence speed of contraction on strength, muscular power, and hypertrophy development, Journal of Strength and Conditioning Research, 1993, vol. 7, 3, pp. 172-178.

[22] Kraemer W. J., Fleck J. S., Strength training for young athletes, Human Kinetics, Champaign IL, 1993, pp. 13-17.

[23] Moss B. M., Refsnes P., Abldgaard A., Nicolaysen K., Jensen J., Effects of maximal effort strength training with different loads on dynamic strength, cross-sectional area, load-power and load-velocity relationships, European Journal of Applied Physiology, 1997, vol. 3, pp. 193-199.

[24] Young W., McLean B., Abangra J., Relationship between strength qualities and sprinting performance, Journal of Sports Medicine and Physical Fitness, 1995, vol. 35, pp. 13-19.

[25] D. A. JONES, 0. M. RUTHERFORD AND D. F. PARKER, PHYSIOLOGICAL CHANGES IN SKELETAL MUSCLE AS A RESULT OF STRENGTH TRAINING, REVIEW ARTICLE Quarterly Journal of Experimental Physiology (1989) 74, 233-256.

[26] Hoffman J., Maresh C., Armstrong L., Kraemer W., Effects of off-season and in-season resistance training programs on a collegiate male basketball team, Journal of Human Muscle Performance, 1991, vol. 1, pp. 48-55.

[27] Hoffman J. R., Kang J., Strength changes during an in-season resistance training program for football, Journal of Strength and Conditioning Research, 2003, vol. 17, 1, pp. 109-114.

[28] Smith M., Melton P., Isokinetic versus isotonic variable resistance training, American Journal of Sports Medicine, 1981, vol. 9, pp. 275-279.

[29] Giorgos P. Paradisis, Athanassios Biss as and Carlton B. Cooke, Effect of Combined Uphill-Downhill Sprint Training on Kinematics and Maximum Running Speed in Experienced Sprinters International Journal of Sports Science \& Coaching Volume 10 Number 52015887.

[30] Pareja-Blanco, F.; Rodriguez-Rosell, D.; Sanchez-Medina, L.; Gorostiaga, E. M.; Gonzalez-Badillo, J. J. Effect of movement velocity during resistance training on neuromuscular performance. Int. J. Sports Med. 2014, 35, 916-924. 
[31] Gonzalez-Badillo, J. J.; Sanchez-Medina, L. Movement velocity as a measure of loading intensity in resistance training. Int. J. Sports Med. 2010, 31, 347-352.

[32] Sheppard, J. M.; Triplett, N. T. Program Design for Resistance Training. In Essentials of Strength Training and Conditioning, $4^{\text {th }}$ ed.; Haff, G. G., Triplett, N. T., Eds.; Human Kinetics: Champaign, IL, USA, 2016; pp.439-470.

[33] H. Lohne-Seiler, M. K. Torstveit, and S. A. Anderssen, "Traditional versus functional strength training: effects on muscle strength and power in the elderly," Journal of Aging and Physical Activity, vol. 21, no. 1, pp. 51-70, 2013.

[34] Groennebaek T and Vissing K (2017) Impact of Resistance Training on Skeletal Muscle Mitochondrial Biogenesis, Content, and Function. Front. Physiol. 8: 713. doi: 10.3389/fphys.2017.00713.

[35] Tarnopolsky, M. A., Rennie, C. D., Robertshaw, H. A., FedakTarnopolsky, S. N., Devries, M. C., and Hamadeh, M. J. (2007). Influence of endurance exercise training and sex on intramyocellular lipid and mitochondrial ultrastructure, substrate use, and mitochondrial enzyme activity. Am J Physiol Regul Integr Comp Physiol 292, R1271-1278.

[36] David H. Fukuda, Jay R. Hoffman, and Jeffrey R. Stout, Strength and Speed/Power Athletes, 2017 by Taylor \& Francis Group, LLC.

[37] Brechue, W. F. 2011. Structure-function relationships that determine sprint performance and running speed in sport. Int $\mathrm{J}$ Appl Sports Sci 23: 313-50.

[38] Watts, A. S., I. Coleman, and A. Nevill. 2012. The changing shape characteristics associated with success in world-class sprinters. J Sports Sci 30: 1085-95.

[39] Aerenhouts, D., C. Delecluse, F. Hagman et al. 2012. Comparison of anthropometric characteristics and sprint start performance between elite adolescent and adult sprint athletes. Eur J Sport Sci 12: 9-15.

[40] McGuigan MR, Newton MJ, Winchester JB, and Nelson AG. Relationship between isometric and dynamic strength in recreationally trained men. J Strength Cond Res 24: 25702573, 2010. 